\title{
Al-Madãris
}

VOL. 2, NO. 1, 2021

E-ISSN: 2745-9950

https://journal.staijamitar.ac.id/index.php/almadaris

\section{FACEBOOK, TWITTER INSTAGRAM \& WHATSAPP SEBAGAI KONSEP NYATA DETERMINISME TEKNOLOGI DALAM MASYARAKAT}

\author{
Muhammad \\ STAI Jamiatut Tarbiyah Lhoksukon \\ mutiaradesal@gmail.com \\ Saifuddin Arsyen \\ STAI Jamiatut Tarbiyah Lhoksukon \\ Saifuddinarsyen68@gmail.com
}

\begin{abstract}
Technological determinism is a theory which asserts that changes that have occurred in technological developments from ancient times to the present have had a major influence on society. Technological developments such as new creations or innovations, new discoveries, and other things aimed at developing technology to facilitate human activities, have a major influence on the development of social values and life in society. Technological determinism is also defined as an autonomous arrangement based on technology which then claims that technology is a dominant factor in the occurrence of social changes, the effects of which depart from the cultural meaning and uses that technology can provide, because basically in technological determinism, The innovations found by inventors in society are also aimed at society. Therefore, technological determinism considers the importance of human ideas in creating technology which then affects human social life.
\end{abstract}

Keywords: Social media, Technology, Determinism, Society

$\overline{\text { Al-Madãris, Volume 2 (1), } 2021}$ 


\section{A. Pendahuluan}

Pada abad ke-2l ini, siapa sih yang tidak mengenal atau bahkan sampai tidak pernah mendengar tentang Facebook dan Twitter. Semua orang pasti mengenalnya, atau paling tidak sudah pernah mendengar namanya. Khususnya di kalangan remaja, hampir seluruh remaja di Indonesia, bahkan mungkin di seluruh dunia mempunyai akun Facebook dan Twitter. Tidak sedikit pula dari anak-anak dan orang dewasa pada masa sekarang ini yang juga telah mempunyai akun di Facebook maupun Twitter. Facebook dan Twitter sudah dapat dibilang sangat mempengaruhi gaya hidup masyarakat, baik itu di Indonesia maupun di dunia. Mereka juga dapat dikatakan sebagai salah satu bentuk nyata konsep determinisme teknologi dalam komunikasi, khususnya komunikasi media massa dalam dunia maya atau media online. Mengapa dapat dikatakan demikian? Hal ini dikarenakan Facebook dan Twitter seakan-akan telah menjadi suatu bagian yang penting dan tidak dapat dipisahkan dalam kehidupan manusia saat ini, khususnya untuk kalangan remaja.

Dengan kemajuan teknologi saat ini berupa handphone hingga smartphone yang dapat digunakan untuk mengakses dunia maya dengan optimal, menjadikan Facebook dan Twitter menjadi lebih dekat dengan penggunanya. Akibatnya, para remaja menjadi seakan mempunai ketergantungan terhadap Facebook maupun Twitter. Hal ini dapat dilihat dalam contoh kehidupan sehari-hari misalnya, remaja saat ini kebanyakan bangun tidur langsung mencari handphone, lalu mengecek notification atau pemberitahuan di Facebook atau melihat mention di Twitter. Mereka tidak lagi menerapkan doktrin lagu "bangun tidur ku terus mandi" seperti pada masa dahulu dalam kehidupan sehari-hari masa kini.

Inilah yang bisa disebut sebagai suatu bentuk nyata konsep determinisme teknologi di mana teknologi sekarang ini sudah memberi peranan penting sehingga sangat mempengaruhi kehidupan masyarakat, dan juga menciptakan perubahan di dalam kehidupan sosial. Penulis memilih tema besar tentang konsep determinisme teknologi (technological determinism) dan gaya hidup masyarakat abad 21 dengan alasan bahwa penulis ingin mengutarakan bahwa masyarakat Indonesia maupun dunia pada masa sekarang sangat dipengaruhi oleh perkembagan atau kemajuan teknologi, khususnya dalam paper ini, penulis ingin membahas tentang eksistensi Facebook, Twitter, Whatsapp dan Instagram.

\section{B. Review Literatur}

Teknologi Komunikasi seperti yang dijelaskan oleh Abrar, dalam Alfira, (2012: 1) meliputi ciri-ciri antara lain sebagai berikut:

a) Alat.

b) Dilahirkan oleh sebuah struktur ekonomi, sosial, dan politik.

c) Membawa nilai-nilai dari struktur ekonomi, sosial, dan politik tertentu.

d) Meningkatkan kemampuan indera manusia. 
Jadi, dapat ditarik kesimpulan bahwa teknologi komunikasi adalah sebuah alat yang dilahirkan oleh struktur dan nilai-nilai ekonomi, sosial, dan politik dalam suatu masyarakat yang berfunsi untuk meningkatkan kemampuan indera manusia. Contoh yang paling sederhana adalah handphone atau ponsel.

\section{Konsep Determinisme Teknologi}

Dalam Kamus Ilmu-Ilmu Sosial, disebutkan bahwa determinism techno-economic, merupakan suatu ajaran bahwa masyarakat sangat ditentukan oleh faktor-faktor teknologi dan ekonomi, (Reading\&Hugo F., 1986: 115). Dari sini dapat ditarik pengertian bahwa determinisme teknologi merupakan suatu ajaran bahwa masyarakat sangat ditentukan oleh faktor-faktor teknologi. Dengan kata lain kemajuan teknologi juga turut menjadi faktor penting dalam menentukan kelangsungan dan kelanjutan kehidupan masyarakat.

Teknologi membentuk individu tentang bagaimana cara erpikir, berperilaku dalam masyarakat, dan teknologi tersebut akhirnya mengarahkan manusia untuk bergerak dari suatu abad ke abad teknologi yang lain, (Nuruddin, 2007: 185). Sedangkan Determinisme Teknologi Media menurut McQuail, (2005: 104) jika diartikan dalam bahasa Indonesia, antara lain adalah sebagai berikut:

a) Teknologi komunikasi merupakan sesuatu yang mendasar pada masyarakat.

b) Setiap teknologi mempunyai bias dalam bentuk komunikasi praktis, isi, dan kegunaannya.

c) Serangkaian penemuan dan penerapan teknologi komunikasi berpengaruh kepada perubahan sosial.

d) Revolusi komunikasi mengarahkan kepada revolusi sosial.

Secara umum, konsep atau teori determinisme teknologi di sini menjelaskan bahwa teknologi komunikasi memiliki peranan yang penting di dalam masyarakat. Arah penemuan teknologi komunikasi dapat mempengaruhi perubahan sosial suatu masyarakat, dan lebih jauh, teknologi komunikasi juga dapat mendorong munculnya revolusi sosial masyarakat, (McQuail, (2005: 104).

\section{Metodelogi}

Metode yang digunakan dalam penelitian ini adalah metode penelitian deskriptif kualitatif. Metode ini merupakan salah satu dari jenis penelitian kualitatif. Tujuan dari metode penelitian ini adalah untuk mengungkapkan kejadian atau fakta, keadaan, fenomena, dan keadaan yang terjadi saat penelitian berlangsung dengan menyuguhkan apa yang sebenarnya terjadi. Penelitian deskriptif kualitatif ini menanfisrkan dan menguraikan data yang bersangkutan dengan situasi yang sedang terjadi, sikap serta pandangan yang terjadi di dalam suatu masyarakat.

Berkaitan dengan penelitian ini, pemilihan metode deskriptif kualitatif digunakan agar peneliti dapat memberikan fakta yang sesuai 
dengan apa yang peneliti temukan selama melakukan penelitian. Hasil dari penelitian tersebut akan peneliti uraikan sejelas-jelasnya. Peneliti memilih metode penelitian deskriptif kualitatif, untuk mengetahui bagaimana sebenarnya determinisme teknologi ditengah gencarnya penggunaan social media (facebook, twitter, whatsapp dan Instagram), dimana ke empat platform media social tersebut sangat mewarnai kehidupan masyarakat saat ini.

\section{Hasil Kajian}

\section{Komunikasi Massa}

Komunikasi massa (mass communication) merupakan proses menciptakan kesamaan arti antara media massa dengan khalayak mereka, (Stanley J. Baran, 2010:7). Komunikasi massa, di abad ke-21 memberikan banyak perubahan besar bagi masyarakat. Tidak dapat dipungkiri bahwa media massa memiliki kekuatan yang besar untuk mengubah masyarakat menuju ke arah yang baru, entah itu perubahan ke arah positif ataupun ke arah negatif, (Fajar, 2012).

Menurut Nurudin dalam bukunya Pengantar Komunikasi Massa (2009:66) dijelaskan bahwa komunikasi mempunyai fungsi antara lain sebagai penyedia dan penyalur informasi, sebagai sarana hiburan, memberikan persuasi, transmisi budaya, mendorong kohesi sosial, melakukan pengawasan, menjalin korelasi, memungkinkan terjadinya pewarisan sosial, dan melawan kekuasaan dan kekuatan represif, serta untuk menggugat hubungan trikotomi.

\section{Media Massa Online}

Dalam Mondry, dijelaskan bahwa media online juga dapat disebut dengan media internet. Sekilas, orang akan menilai bahwa media online termasuk dalam media elektronik, namun para pakar mengelompokkannya sendiri. Alasannya adalah karena media online menggunakan gabungan proses media cetak dengan menulis informasi yang disalurkan melalui sarana media elektronik. Media online juga biasa diebut dengan sebutan media baru, (Mondry, 2008:12).

\section{a) Facebook}

Menurut definisi pribadi penulis, dengan melihat karakteristik yang ada dan tampak pada halaman Facebook, maka penulis dapat mendefinisikan bahwa Facebook merupakan situs jejaring sosial dengan basis di mana penggunanya dapat membuat akun pribadi, kemudian menambahkan orang lain sebagai teman, melakukan pertukaran pesan, dan mengirim postingan-postingan ke kronologi (timeline) teman (dulu disebut dengan dinding / wall), mencolek (walaupun sampai sekarang penulis belum tahu apa esensi dari fitur ini), dan yang paling penting adalah adanya fitur "update status" yang memungkinkan penggunanya untuk membagikan kegiatan apa yang sedang dilakukannya kepada pengguna lain, dan juga notification atau pemberitahuan yang secara 
otomatis muncul ketika ada orang yang melakukan interaksi dengan akun kita.

Facebook juga bisa digunakan sebagai sarana berbagi, entah itu foto, video, maupun link (tautan) internet. Bahkan dengan adanya fitur like (suka) dan fitur share (bagikan), kita tidak hanya bisa membagikan status, foto, video, maupun link pribadi kita, namun kita dapat pula untuk membagikan status, foto, video, dan link yang dipunyai oleh akun teman Facebook kita. Selain itu Facebook juga dapat merangkul orang banyak yang mempunyai kesamaan dalam suatu hal yang spesifik, misalnya pekerjaan atau hobi melalui group dan fanpage. Ia juga mempunyai banyak aplikasi dan game yang dapat diakses antar penggunanya secara online seperti "Zinga Poker" dan lain-lain untuk menarik perhatian yang lebih, khususnya remaja dan anak-anak. Lebih jauh, Facebook juga dapat digunakan sebagai sarana beriklan dan juga berbagi informasi seperti berita, isu, dan lain sebagainya.

b) Twitter

Twitter, menurut pandangan pribadi penulis merupakan suatu situs yang hampir mirip dengan jejaring sosial, namun tidak seperti Facebook yang murni menyediakan fitur jejaring sosial yang luas. Twitter lebih kepada sebuah situs micro-blogging yang menyediakan penggunanya untuk membuat akun, kemudian mem-follow pengguna lain, dan juga mengakses pesan pribadi dalam bentuk direct message atau yang lebih sering disebut dengan DM. Esensi dari Twitter lebih kepada pembagian kegiatan kita dalam bentuk tweet (biasa dikenal dengan sebutan nge-tweet) semacam update status di Facebook namun hanya dibatasi sepanjang 140 karakter, dan juga fitur mention yang selalu dinanti-nantikan oleh masingmasing pengguna untuk melihat siapa saja orang yang baru berinteraksi dengan kita. Hubungan pertemanan di Twitter juga hanya terpaut pada adanya fitur follow sehingga muncul istilah follback atau singkatan dari follow back yang terjadi di antara penggunanya.

Dalam Twitter tidak ada fitur group layaknya di Facebook, jadi akun Twitter lebih bersifat personal, sehingga seakan-akan kita seperti mengolah sebuah blog kecil dengan tulisan-tulisan kita yaitu tweet-tweet yang kita bagikan tadi. Karena tidak ada group seperti di Facebook, menjadikan akun resmi dari seseorang atau lembaga yang penting biasanya mempunyai jumlah followers yang melimpah. Twitter juga biasa digunakan untuk menjaring lebih banyak follower dengan dibentukanya akun-akun yang mencerminkan kehidupan saat ini khususnya remaja, seperti akun yang berisi humor, plesetan, teka-teki, tips-tips biar gak galau dan agar bisa move on dari mantan, dan lain sebagainya.

c) Instagram, media sosial tempat berpamer foto

Selain Youtube, Instagram pun hadir dengan media sosial berbasis media grafis sebagai konten utama nya. Dengan fitur like dan comments, serta direct message, para pengguna bisa saling berinteraksi, baik itu hanya saling me-Like foto, maupun pun berkomentar di gambar unggahan. 
Bukan hanya itu, Instagram pun kini dilengkapi dengan fitur story, dimana pengguna bisa mengunggah video singkat yang hanya bisa diakses dalam waktu 24 jam. Satu fitur yang unik di Instagram adalah memotong foto menjadi bentuk persegi, sehingga terlihat seperti hasil kamera Kodak Instamatic dan polaroid. Hal ini berbeda dengan rasio aspek 4:3 yang umum digunakan oleh kamera pada peranti bergerak.

Awalnya, Kevin dan Mike menciptakan aplikasi mobile web bernama Burbn. Aplikasi ini punya fitur semacam check-in lokasi, pengguna akan mendapatkan poin di aplikasi ini setiap kali mereka check-in saat bergaul dengan teman, posting foto, dan banyak lagi. Tapi, karena fitur di dalam aplikasi Burbn terlalu banyak, mereka membuat aplikasi baru yang lebih simple yaitu Instagram. Jika aplikasi yang terdahulu punya banyak fitur, Kevin dan Mike sengaja membuat Instagram hanya dengan 3 macam fitur, yaitu posting foto, komentar dan like. Jadi, pengguna Instagram tidak perlu repot atau bingung untuk menggunakan social media ini. Nama Instagram diambil dari kata "insta" yang berasal dari kata "instan". Kata instan juga diambil dari cara kerja kamera Polaroid yang menghasilkan foto secara instan. Maka, lambang Instagram mirip seperti kamera Polaroid. Sedangkan "gram", diambil dari kata "telegram" yang berarti cara kerjanya mengirimkan informasi secara cepat, (gudangilmukomputer.com: akses, 02-03-2021).

d) Berbagai media sosial berbasis layanan pesan singkat

Belakangan, kemunculan Whatsapp, Line, We Chat, Kakao Talk dan yang lainnya terus menambah panjang daftar situs-situs jejaring sosial yang sudah ada. Nama-nama aplikasi terakhir tersebut merupakan bagian dari media sosial yang berbasiskan media untuk saling berkirim pesan singkat. Hampir mirip dengan fitur dari SMS yang sudah lama muncul, namun yang membedakannya adalah penggunaan dari media sosial tersebut membutuhkan koneksi internet. Selain itu, pengguna juga dapat melakukan pencarian kontak orang yang telah atau akan dikenal dengan memanfaatkan fitur pencarian dengan menggunakan user id maupun memanfaatkan jarak kedekatan tempat antar pengguna. Hal ini merupakan perkembangan dari aplikasi pendahulunya, yaitu Blackberry Messenger yang mengandalkan fitur pin khusu bagi tiap pengguna, yang nantinya digunakan sebagai media untuk menambahkan daftar pertemanan di daftar kontak para pengguna.

Salah satu dari keunggulan media sosial berbasis pengiriman pesan singkat seperti Blackberry Messenger, Whatsapp, Line, We Chat, Kakao Talk, dan sebagainya yaitu fitur chat group dan broadcast. Dalam hal chat group, para pengguna dapat membentuk suatu kelompok obrolan chat yang berisikan orang-orang tertentu, dengan kriteria yang disepakati bersama, seperti grup obrolan keluarga besar, grup obrolan alumni, grup obrolan kelompok belajar, dan sejenisnya. Tentu fitur ini memudahkan pengguna dalam saling berinteraksi dalam suatu wadah dengan kesamaan latar belakang. Hal ini jelas menjadikan obrolan semakin mudah dan efektif dalam menangani masalah komunikasi antar pengguna, terutama dalam hal jarak yang selama ini menjadi kendala. Adapun untuk fitur Al-Madãris, Volume 2 (1), 2021 
Broadcast, pengguna bisa mengirimkan suatu pesan ke banyak kontak yang ada dalam daftar kontak masing-masing pengguna, dan biasanya dimanfaatkan untuk pesan berantai.

\section{E. Pembahasan}

Jika dikaitkan dengan perkembangan teknologi komunikasi, baik Facebook maupun Twitter sama-sama merupakan suatu bentuk sarana yang ada di dalamnya. keduanya mempunyai hubungan yang erat dengan wujud teknologi komunikasinya yang berupa komputer, dan juga media online atau media baru. Bahkan agar lebih dekat dengan masyarakat, maka Facebook dan Twitter juga disediakan untuk dapat diakses melalui ponsel (handphone), terlebih untuk dewasa ini keduanya juga sering disajikan dalam bentuk aplikasi yang terintegrasi atau bisa diunduh untuk dipasang di ponsel.

Facebook dan Twitter merupakan suatu bentuk jejaring sosial atau microblog yang diciptakan guna menghubungkan antara satu pengguna dengan pengguna yang lainnya. Keduanya dibentuk untuk tujuan agar penggunanya bisa mengenal lebih dekat satu sama lain, dan juga tetap dekat walaupun mereka dipisahkan oleh suatu jarak yang jauh. Misalnya seseorang dengan saudaranya yang berada di luar negeri, masih bisa saling berinteraksi langsung melalui Facebook dan Twitter. Bahkan sekarang ini, Facebook sudah dilengkapi dengan fitur video chat, yang memungkinkan satu pengguna dan pengguna yang lain untuk bisa berkomunikasi sekaligus bertatap muka, layaknya chatting dengan Yahoo Messenger, dan aplikasi chatting lainnya. Facebook dan Twitter juga sering digunakan untuk menghubungkan selebritis atau public figure dengan para fansnya, biasanya dalam bentuk group dan fanpage untuk Facebook. Sedangkan dalam Twitter, biasanya untuk verified account atau akun resmi dari seorang public figure mempunyai jumlah follower yang banyak.

Dikaitkan dengan peranannya dalam komunikasi massa, Facebook dan Twitter memang benar-benar memiliki kekuatan yang sama dengan komunikasi massa, seperti yang dikatakan Fajar (Maret 2012) bahwa komunikasi massa punya peranan yang besar untuk mengubah masyarakat ke arah yang baru, baik itu positif maupun negatif. Menuju ke arah yang positif, di sini Facebook dan Twitter sering digunakan sebagai sarana penyampaian informasi. Kita sering melihat di website lain selain Facebook dan Twitter, misalnya portal berita online, blog, dan lain-lain telah menerapkan fitur "share with Facebook" atau "share with Twitter". Biasanya dalam suatu artikel atau berita, di bagian bawah dari berita atau di tepian margin berita atau artikel terdapat ikon 'share' dengan diikuti simbol huruf 'f' untuk Facebook dan huruf ' $t$ ' untuk Twitter.di sini jelas membuktikan bahwa Facebook dan Twitter memenuhi peranannya sebagai bagian dari bentuk komunikasi massa, yaitu berfungsi sebagai pemberi informasi. Sepertinya lebih tepat jika disebut sebagai penyalur informasi, karena informasi yang berasal dari luar (website lain) kemudian

$\overline{\text { Al-Madãris, Volume 2 (1), } 2021}$ 
kita bantu bagikan kepada orang lain melalui "share with" Facebook dan Twitter tadi.

Jadi, peranan keduanya di sini lebih kepada menjadi link atau penghubung beragam informasi, baik itu berita, isu, puisi, foto, video, dan beragam bentuk karya lain untuk disalurkan kepada lebih banyak orang. Hal ini dikarenakan masyarakat saat ini cenderung lebih mengetahui tentang hal baru lainnya berasal dari Facebook dan Twitter daripada langsung dari website aslinya. Misalnya kita lebih cenderung mengetahui berita tentang Kemenangan Jokowi pada Pilgub DKI tahun lalu melalui timeline akun Twitter detik.com (@detikcom) kemudian baru kita membaca artikelnya secara lengkap di website aslinya, daripada kita harus langsung membuka detik.com untuk mencari artikel tentang berita tersebut. Inilah yang merupakan salah satu bentuk nyata dari penggunaan Facebook dan Twitter sebagai sarana penyalur informasi kepada masyarakat yang lebih luas.

Hal positif lainnya dapat dibuktikan dengan Facebook dan Twitter yang digunakan sebagai sarana persuasi kepada publik. Misalnya dalam dunia internasional, pemberitaan kampanye pemilihan presiden Amerika Serikat Barrack Obama, yang masiv di kalangan dunia. Hampir semua orang di seluruh dunia mengetahui hal ini. Selain itu efek agenda setting media yang memberikan kesan-kesan baik pada Obama sehingga kemudian muncullah keyakinan bahwa Obama pantas untuk dipilih menjadi presiden, ditambah dengan disebarluaskannya agenda media tadi melalui Facebook dan Twitter, sehingga persuasi politik Obama dan media AS menjadi efektif dan tersampaikan dengan baik dan meluas, serta kemudian berimplikasi pada terpilihnya Obama sebagai presiden AS.

Contoh lainnya yak ni pada saat sebelum pilgub DKI dilaksanakan, salah satu public figure, Addie MS melalui akun twitternya menuliskan sesuatu yang kontroversial. "Foke-lah kalau begitu", kata-kata itulah yang kira-kira dilontarkan atau dituliskan oleh Addie dalam akun twitternya. Secara otomatis masyarakat akan memandang bahwa Addie MS mendukung Foke dalam pilgub DKI, namun kenyataanya tidak demikian. Hal ini kemudian memunculkan ribuan balasan tweet dari berbagai kalangan masyarakat yang menuduh Addie mempunyai koalisi dengan Foke, Addie mendukung Foke, dan lain-lain. Bahkan sampai muncul tweet balasan kepadanya dengan kata-kata "Fokoke Jokowi", yang bisa diartikan mau tidak mau harus Jokowi yang terpilih menjadi Guberbur DKI. Ini membuktikan bahwa Facebook atau Twitter merupakan sarana yang bisa digunakan untuk mempersuasi publik walaupun hanya dengan satu kalimat. Khususnya di sini public figure, punya peluang yang sangat besar untuk menggeser atau menggiring opini publik melalui akun di Facebook atau Twitternya. Sungguh merupakan kemajuan teknologi yang berdampak besar bagi masyarakat Indonesia maupun masyarakat di dunia.

Namun bukan berartiu kemajuan teknologi dengan wujud dibentuknya Facebook dan Twitter hanya memunculkan perubahan ke 
arah yang positif saja. Bagaimana pun masih banyak contoh perubahan sosial yang menggiring masyarakat kepada arah perubahan yang negatif. Dari sini muncul permasalahan dalam interaksi antar pengguna Facebook dan Twitter. Sebenarnya tidak jadi masalah jika interaksi dilakukan via Facebook untuk dua orang yang dipisahkan oleh ruang dan jarak. Namun akan sangat jadi ironis jika ternyata antar pengguna satu dengan yang lainnya menggunakan Facebook untuk berinteraksi dan berkomunikasi secara berlebihan, padahal si kehidupan setiap harinya sebenarnya ia juga bisa bertemu untuk bertatap muka dan berkomunikasi dengan cara yang wajar saja.

Misalnya saja ada dua remaja yang sedang menjalin hubungan atau berpacaran di kehidupan nyata, kemudian memasang status di info profil Facebooknya dengan kata-kata 'berpacaran', bermesra-mesraan di Facebook dengan postingan-postingan di wall atau timeline yang berlebihan, mengumbar kata-kata cinta yang berlebihan pula di status update, mengunggah foto-foto mesra, dan lain-lain yang seakan-akan Facebook hanyalah milik mereka berdua. Di sini, Facebook seakan menjadi teman curhat, dari yang penting sampai yang tidak penting sama sekali. Bahkan ada yang mengaku-ngaku bahwa mereka masih berpacaran padahal dalam kenyataanya sudah putus, ada juga yang menutup-nutupi bahwa mereka tidak sedang ada masalah padahal dalam kenyataannya muncul masalah yang serius.

Dari hal tersebut dapat dikatakan bahwa Facebook (tidak menutup kemungkinan juga terjadi pada Twitter) akan membuat perubahan ke arah yang negatif jika digunakan sebagai ajang eksplorasi yang berlebihan. Selain itu, apa yang disampaikan belum tentu juga merupakan suatu kebenaran atau hanyalah merupakan sebuah cerita fiktif atau kebohongan belaka. Terlebih lagi jika hal ini dilakukan dalam jangka waktu yang lama, akan berdampak pada berkurangnya inensitas interaksi langsung pada masyarakat. Mereka akan cenderung lebih antisosial dengan orang lainnya jika mereka hanya suka berdiam diri saja di rumah dan hanya berinteraksi melalui Facebook dan Twitter daripada harus keluar rumah untuk berinteraksi secara langsung dengan sesamanya.

Seperti yang dijelaskan dalam konsep determinisme teknologi, di mana kemajuan teknologi sangat berpengaruh terhadap arah penemuan baru dan mempunyai peranan penting untuk membentuk perilaku masyarakat yang memungkinkan terjadinya perubahan dan juga revolusi sosial. Dalam kehidupan sehari-hari, Facebook dan Twitter dirasa telah menjadi bagian yang penting dalam kehidupan masyarakat, khususnya para remaja. Hal ini dapat dilihat seperti dalam kehidupan sehari-hari, misalnya mahasiswa yang bangun tidur bukannya langsung mandi, tetapi malah sibuk mencari ponselnya untuk mengecek apakah ada notification di facebooknya ataukah mungkin ada mention di twitternya. Merupakan suatu perubahan sosial yang sepertinya terlihat biasa sepele, namun dampaknya terjadi secara masiv dan sungguh terlihat serta terasa, karena

Al-Madãris, Volume 2 (1), 2021 
yang terjadi adalah perubahan pada pola pikir dan pola perilaku serta kebiasaan para remaja.

Contoh lain misalnya seperti pada saat perkuliahan, amahasiswa yang mudah bosan dengan materi perkuliahan akan cenderung mengambil ponselnya dari saku atau tas, kemudian membuka opera mini atau browser lainnya, lalu mengakses Facebook atau Twitter. Ini merupakan kejadian sepele, namun jika dilakukan terus menerus, dampaknya juga akan kembali ke mahasiswa tadi. Misalnya saja kemudian ada dosen yang tidak terima jika ada mahasiswanya yang kedapatan sedang bermain ponsel ketika beliau sedang menjelaskan materi, sehingga pada akhirnya menyuruh mahasiswa tersebut untuk keluar dari ruang kelas. Atau lebih jauh jika saat kuliah hanya bermain ponsel untuk facebook-an atau twitteran, maka ia juga tidak akan mendapatkan ilmu apa-apa, bukan? Jika hal ini terjadi pada suatu kelompok diskusi maka mahasiswa tersebut cenderung untuk pasif dan bersifat groupthink. Sungguh sangat disayangkan apabila benar-benar terjadi seperti demikian. Facebook dan Twitter pada mulanya tidak dibuat untuk mengubah perilaku atau aspek afektif masyarakat khususnya para remaja untuk berubah menuju ke arah yang negatif. Namun jika mereka salah dalam memanfaatkannya atau tidak mempergunakannya sebagaimana mestinya, maka akan memunculkan kerugian di dalamnya.

Dari sini dapat ditarik kesimpulan bahwa Facebook dan Twittermerupakan suatu bentuk perwujudan nyata dari konsep atau teori tentang determinisme teknologi. Keduanya, seperti dikaitkan dalam peranan teori tersebut, merupakan suatu bentuk lain teknologi komunikasi yang mempunyai peranan penting dalam kaitannya dengan komunikasi massa, untuk menyampaikan atau menyalurkan informasi, dan juga membentuk serta menggiring opini publik dengan cara-cara yang persuasif. Lebih jauh, Facebook dan Twitter dirasa telah menjadi bagian yang penting dalam kehidupan masyarakat baik di Indonesia maupun di kancah dunia, sehingga perlahan-lahan telah membentuk perubahanperubahan perilaku yang tidak disadari oleh penggunanya atau masyarakat luas. Dampak di sini lebih kepada aspek afektif dan perilaku masyarakat, khususnya perilaku remaja. Revolusi atau perubahan sosial yang muncul akibat Facebook dan Twitter mungkin akan bertahan selama keduanya masih tetap eksis dan menjadi bagian penting tersendiri dalam kehidupan masyarakat di abad ke-2l.

\section{F. Kesimpulan}

Masyarakat sudah terhipnotis dengan media sosial sehingga apapun mereka bagi dalam dunia sosial bahkan hingga hal-hal yang sifatnya pribadi. Transisi antar era dalam determinisme teknologi tadi tidaklah bersifat gradual atau evolusif, akan tetapi lebih disebabkan oleh penemuan teknologi komunikasi. Inti dari teori McLuhan adalah penemuan atau perkembangan teknologi komunikasi itulah yang sebenarnya yang mengubah kebudayaan manusia. Jika Karl Marx 
berasumsi bahwa sejarah ditentukan oleh kekuatan produksi, maka menurut McLuhan eksistensi manusia ditentukan oleh perubahan komunikasi yang dipengaruhi oleh perkembangan teknologi sehingga melahirkan era baru atau revolusi kehidupan masyarakat.

Tergambar jelas bahwa masyarakat adalah objek dari teknologi dan media merupakan salah satu alat yang digunakan untuk menyebarkan teknologi. Media jenis apapun harus bergerak cepat mengikuti perkembangan teknologi demi memenuhi keinginan khalayak dan teknologi sangat mempengaruhi pola konsumsi khalayak terhadap media. Media sosial sebagai media baru menawarkan kecepatan dan kebaruan informasi, interaksinsosial yang lebih kompleks. Pembaruan dan update yang begitu cepat dalam fitur media sosial timbul karena adanya interaksi antara individu yang satu dengan yang lainnya, ini yang membedakan media lama dan media baru. Interaksi antar individu masyarakat menjadi sangat kompleks. Media dalam bentuk apapun merupakan alat untuk memperluas dan memperkuat pengaruhnya dalam pemikiran dan tindakan manusia. Kenyataan ini menunjukkan, masing-masing penemuan teknologi media baru yang betul-betul dipertimbangkan untuk memperluas dan kecakapan manusia.

\section{BIBLIOGRAFI}

Alfira, Nisa. (2012). Perkembangan Teknologi Komunikasi: Pengantar. Materi kuliah Perkembangan Teknologi Komunikasi, Jurusan Ilmu Komunikasi FISIP UB, Malang.

Anggi. (2012). Strategi Komunikasi dan Kampanye Politik (pernyataan langsung). Materi kuliah Komunikasi Politik, Jurusan Ilmu Komunikasi FISIP UB, Malang.

Baran, Stanley J. (2010). 'Introduction to Mass Communication: Media Literacy and Culture (6th ed.)', dalam Wulung Wira Mahendra, penerj. (2011). Pengantar Komunikasi Massa: Literasi Media dan Budaya. Jakarta: Salemba Humanika.

Croteau, David., \& Hoynes, William. (1997). Media Society: Industries, Images and Audiences. PineForge Press. London.

Fajar, Dewanto Putra. (2012). Komunikasi Massa di Abad 21. Materi kuliah Komunikasi Massa, Jurusan Ilmu Komunikasi FISIP UB, Malang.

Fajar, Dewanto Putra. (2012). Teori-Teori Media dan Masyarakat. Materi kuliah Komunikasi Massa, Jurusan Ilmu Komunikasi FISIP UB, Malang.

Fusch, Christian. (2017). Social Media: A Critical Introduction (2nd Edition). California: SAGE Publication Ltd.

McQuail, Denis. (2005). Mass Communication Theory (5th ed.). California: Sage Publication Ltd.

Mondry. (2008). Pemahaman Teori dan Praktik Jurnalistik. Bogor: Ghalia Indonesia. Nurudin. (2007). Pengantar Komunikasi Massa. Jakarta: Raja Grafindo Perkasa.

Nurudin. (2009). Pengantar Komunikasi Massa. Jakarta: Rajawali Pers.

$\overline{\text { Al-Madãris, Volume 2 (1), } 2021}$ 
Reading, Hugo F. (1986). Dictionary of Social Science; Kamus Ilmu-Ilmu Sosial (Sahat Simamora, Terjemahan). Jakarta: Rajawali.

Saefudin, Asep. (2008). Perkembangan Teknologi Komunikasi: Perspektif Komunikasi Peradaban. Jurnal Mediator, (9)2.

Surahman, Sigit. (2016). Determinisme Teknologi Komunikasi Dan Globalisasi Media Terhadap Seni Budaya Indonesia. Jurnal Rekam, (12)1.

Puntoadi, Danis. (2011). Menciptakan Jualan Melalui Sosial Media. Jakarta: Elex Media Komputindo.

$\overline{\text { Al-Madãris, Volume 2 (1), } 2021}$ 